\title{
Forensic Biomechanics
}

\section{Engin $\mathrm{AE}^{*}$}

Professor Emeritus, The Ohio State University\& University of South Alabama, Department of Mechanical Engineering, Shelby Hall 3128, USA

*Corresponding author: Engin AE, Department of Mechanical Engineering, Shelby Hall 3128, AL, USA, Tel: (251) 460-7454; Fax: (251)460-6549; E-mail: aeengin@southalabama.edu

Received date: Jan 02, 2014: Accepted date: Jan 07, 2014: Published date: Jan 13, 2014

Copyright: $@ 2014$ Engin AE. This is an open-access article distributed under the terms of the Creative Commons Attribution License, which permits unrestricted use, distribution, and reproduction in any medium, provided the original author and source are credited.

\section{Editorial}

I would like to start this editorial by acknowledging the Founding Editor-in-Chief of the Journal of Forensic Biomechanics (JFB), namely, the distinguished scientist Dr. Daniel J. Schneck. I was invited by him to serve as the next Editor-in-Chief of JFB about three years ago. Let us first take look what we mean by the terms of "Biomechanics" and "Forensic Biomechanics".

We can define biomechanics as mechanics applied to biology, in particular, to human biology. Considering both mechanics and biology are very broad fields, one immediately realizes the very large number of topics which can be studied and investigated. Some of these topics are in their early stages of development. Research areas and topics in biomechanics can be viewed in a wide spectrum ranging from microscopic scale dealing with individual cells to macroscopic scale dealing with large organisms, human body being the center of attraction. Considering the human body is our main interest and concern within this wide spectrum, we can identify four divisions of research.

The first division deals with the study and determination of the mechanical properties of biological materials starting with individual cell, going through various soft and hard tissues and ending up with organs and complex body systems. The second division is concerned with analyses of the human body to physiological forces. This division includes topics such as locomotion, respiration, circulation, and microcirculation. Analyses of responses of the human body to replaced parts and assistive devices constitute the third division. Both internal and external prosthetic and orthotic devices and biomechanical compatibility of these devices make up the major research areas in the third division. In the fourth and the final division we consider analyses of responses of the human body to forces whose origins are external to the body. In this division all kinds of steady-state, transient, and random types of force and pressure applications can be cited. The nature of forces can be further classified as impact and impulsive type. An impact type of force requires contact of a particular body segment with an external object, whereas impulsive force on a body segment is caused by purely inertial type of loading without a contact with an external object.

The term "Forensic Biomechanics", simply stated, is the application of biomechanics to answer certain scientific questions of civil and criminal law in the judicial system. In the last four decades biomechanics experts have been recognized and admitted to the courts as expert witnesses in order to provide opinions in the forensic biomechanics field. Thanks to the efforts of a good number of individuals, the science of biomechanics is now accepted by the officers of the judicial system. In spite of the fact that the most obvious utilization of forensic biomechanics is in the area of analyses of injury mechanisms associated with motor vehicle accidents, there are other areas such as occupational, sports and recreational, slip/trip and fall accidents, various product liability cases, and safety standards where forensic biomechanics knowledge and expertise is required.

The Journal of Forensic Biomechanics is an open access, peerreviewed journal. The journal publishes research papers, reports of experimental investigations, case studies, historical surveys, and review articles that address the application of biomechanics knowledge and principles to answer certain scientific questions in civil and criminal law cases. For more information regarding the Journal of Forensic Biomechanics, I invite you to visit the website: http:// www.omicsonline.com/open-access/forensic-biomechanics.php

I also invite you to consider submitting a manuscript related to any of the aforementioned topics for publication in this journal. 